\title{
Glucose tolerance, plasma lipids and atherosclerosis
}

\author{
By H. Keen, Unit for Metabolic Medicine, Department of Medicine, Guy's Hospital \\ Medical School, London SEI ${ }_{9} R T$
}

\section{Introduction}

The problem of atherosclerosis is one of great complexity. Clinically we are concerned with an end result - arterial obstruction - which is the resultant of a multitude of precursor mechanisms, some external, some internal, many of them interdependent and interacting. We may start with our particular area of study, but if we follow it through, it will often become confluent with others starting elsewhere. Even when all the mechanisms are identified it will require computer techniques to describe the interplay of all the variables. In the face of this 'multifactorial' complexity the clinician may lose heart, but should not, for it is likely that these many 'causes' converge and produce their 'effect' by way of only a few final pathways. We should certainly continue to try to identify and correct main causal mechanisms, but we can also hope to prevent or modify the disease by manipulation of the final pathways.

\section{Metabolic factors in atherogenesis}

Disturbances of metabolism indicated by glucose intolerance and distortions of plasma lipids have come to be clearly associated with arterial disease in man, particularly over the last 20 years (Gofman, Hanig, Jones, Lauffer, Lawry, Lewis, Mann, Moore, Olmsted, Yeager, Andrus, Barach, Beams, Fertig, Page, Shannon, Stare \& White, 1956; Epstein, 1967). Although the connexion between carbohydrate and lipid metabolism has been obvious since geese fed on grain obligingly produced foie gras, the nature of the link between blood sugar responses and plasma lipids is only now being defined and explained. Interest in hyperglycaemia and hyperlipidaemia originated from the distinctive clinical disorders of diabetes mellitus and familial hypercholesterolaemia, but has now extended into much wider areas of lesser abnormality, usually bereft of symptoms and definable only as a chemical deviation from the norm. In the main, this problem has been brought to light by the application of simplified biochemical technology to large population samples and interest in it stimulated by the promise of preventive opportunities in those considered 'at risk'.

Diabetes and glucose intolerance. The evolution of the concept of diabetes mellitus provides an excellent illustration of this 'diagnostic expansion'. It also indicates the close interrelation between disturbances of glucose and lipid metabolism. The classical view of diabetes mellitus, from which it originally received its name, was of a 
severe, dramatic disease marked by a profusion of striking symptoms and termination in wasting, coma and death. Over the last century the diagnosis has been applied to increasing numbers of people as those found to qualify for the diagnosis have included more and more with undeniable rises of blood sugar and impairment of glucose tolerance but few or no symptoms. The special liability of this group of comparatively 'mild' diabetics to the vascular consequences of diabetes - many of which are anything but 'mild' - was the main motive force behind the drive to secure earlier diagnosis and, hopefully, more effective treatment. It was this silent presence of diabetes which led many investigators out of the hospital clinics into the community to seek out the unsuspected cases and to make more accurate assessments of the size of the problem.

The Bedford survey. In 1962, the Department of Medicine at Guy's Hospital involved itself in a population survey in the town of Bedford (Sharp, Butterfield \& Keen, 1964). About 25000 people were screened for diabetes by testing urine samples for glucose and performing modified glucose tolerance tests - a single capillary blood sugar estimate $2 \mathrm{~h}$ after $5^{\circ} \mathrm{g}$ oral glucose had been given - on the positives. To establish a range of normal values, a random sample, about one in fifty of the whole co-operating population, stratified by age and sex, was submitted to a full standard oral glucose tolerance test. The results of this search for normal standards may be summarized as follows.

At all ages, there was considerable variation of glucose tolerance in the random population sample. In consecutive age groups, there was both a mean rise in blood sugar levels after giving glucose and also an increase in the variation about the mean. At no age was there an indication of a break in the distribution of glucose tolerance into 'normal' and 'abnormal' subgroups. From the clearly non-diabetic on the one hand to the clearly diabetic on the other there was a continuum of responses. The application of fixed diagnostic criteria thus led to a great apparent increase of the number of 'cases' with age. In the Bedford adult population the over-all estimate of frequency of diabetes based on this sample was approximately $14 \%$. Similar blood sugar studies of other large population samples, in the USA (Gordon, r964), in France (Eschwège, I 967) $^{\text {) }}$ in Japan, (Mimura, Oshiro, Koganemaru, Haraguchi, Jinnouchi \& Haraguchi, 1964), and in Australia (Welborn, Curnow, Wearne, Cullen, McCall \& Stenhouse, 1968) led to similar conclusions, though other interpretations have recently been put forward (Bennett, Burch \& Miller, I971).

Associations of glucose intolerance. We concluded that it was fruitless to continue to argue whether all these people with a small rise of blood sugar, or loss of glucose tolerance, were 'diabetic' or not. Much more to the point was the question of whether lesser degrees of glucose intolerance conferred a significantly increased risk of adverse consequences and, if so, whether anything could be done to reduce this hazard. An increased likelihood of arterial disease was a principal consideration. Although generations of medical students had been taught that diabetes was associated with coronary disease, with gangrene and claudication, and with strokes, there was still controversy as to whether the relationship was real or not (Mitchell \& Schwartz, 1965; Pyke, I968). Over the last decade, the case for a relationship has become 
almost overwhelming and there have been several lines of evidence which have established it. The population-based studies in Framingham (Kannel, Castelli \& McNamara, 1967) and the cohort study of diabetic employees of the Dupont Company (Pell \& D'Alonzo, 1970) confirmed the two- to three-fold increase in cardiovascular morbidity and mortality in diabetics compared with non-diabetics; a load which, although it falls particularly heavily upon diabetic women, also imposes a severe extra mortality and morbidity upon diabetic men. Another view of the relationship between raised blood sugar and arterial disease is gained by carrying out a metabolic study of ostensibly non-diabetic people presenting with coronary disease and intermittent claudication. Wahlberg ( 1966 ) in Sweden, Kingsbury (1966) in England, and Tzagournis, Seidensticker \& Hamwi (I967) in the USA showed the greatly increased frequency of varying degrees of glucose intolerance in arteriosclerotic subjects compared with suitable controls.

Blood sugar and arterial disease in Bedford. Further confirmatory evidence of the association came from the population we studied in Bedford. We assembled three groups, characterized only by their glucose tolerance. Our I I 7 newly found diabetics constituted one group, 248 people with mild glucose intolerance, whom we termed 'borderline diabetics', constituted a second, and the third, a normal control of $2 \mathrm{r}_{4}$ was matched for age and sex with the borderline group and made up from those whose tests had disclosed 'normal' glucose tolerance. The relative prevalence of arterial disease in these three blood sugar groups, allowing for the small differences in age and sex composition between the groups, is shown in Fig. I. Compared with the normoglycaemic control, there is an approximately twofold increase of arterial disease in the clearly diabetic group; the borderline diabetics occupy an intermediate position in prevalence. The three blood sugar groups were reassessed

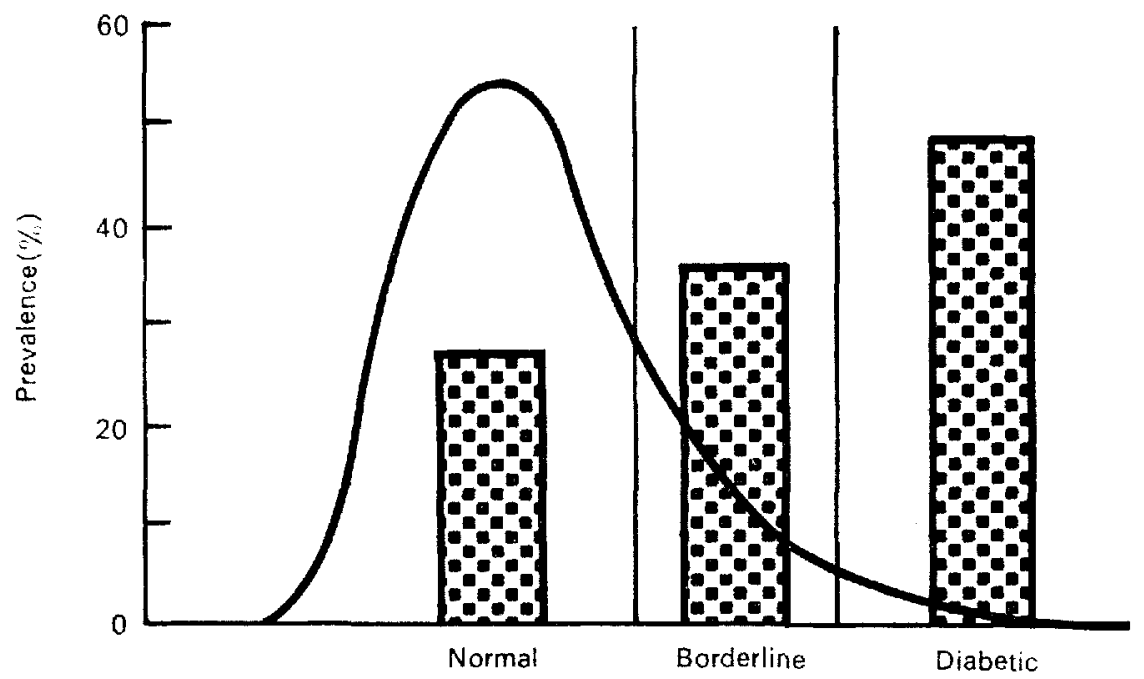

Fig. 1. The prevalence of arterial disease in individuals in representative samples of the three blood sugar groups at the time of the Bedford survey in 1962 is indicated by the heights of the columns. The positively skewed, unimodal distribution curve represents the glucose tolerance in the population. Arterial disease was assessed from evidence obtained by a clinical questionnaire on coronary and leg artery disease and Minnesota code electrocardiographic abnormalities suggesting coronary disease. 


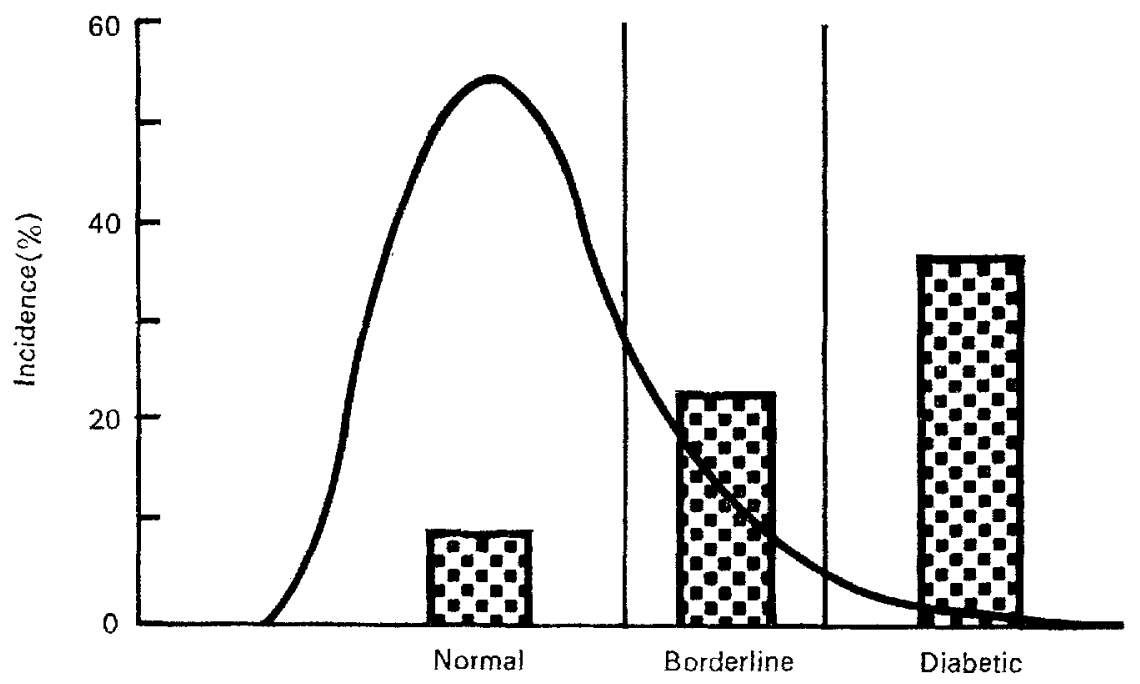

Fig. 2. The relative incidence of new arterial 'events' over an approximately 5-year follow-up period on the three blood sugar groups shown in Fig. I. Only information from the clinical questionnaire and certified cause of death have been used to calculate rates.

approximately 5 years later in 1967 and the relative frequency, corrected for age and sex, of new clinical arterial events experienced during that time is shown in Fig. 2. The gradient of incidence with blood sugar is much steeper than that of prevalence, with a four- to five-fold excess in the diabetics and, again, an intermediate increase in incidence in borderline diabetics. Not only did these findings support the reality of the association between clearly diabetic degrees of glucose intolerance and increased atherosclerotic disease, but they also suggested the existence of a relationship between them at subclinical levels of intolerance (Keen, 1971). This gave some justification for regarding glucose intolerance as a quantitative risk factor in relation to arterial disease, rather than invoking 'diabetes' as a qualitative 'all or none' indicator. Several other population studies elsewhere in the world, notably that in Tecumseh, USA (Ostrander, Francis, Hayner, Kjelsberg \& Epstein, 1965), in Busselton, Australia (Welborn, Jenkins, Cumpston, Curnow, Goff, Johnstone, Stenhouse \& Summers, 1970), and in Paris, France (Gelin, Elgrishi, Ducimetière \& Richard, 1967), also showed the association between glucose intolerance and arterial disease on an epidemiological basis.

\section{Mechanisms of atherogenesis}

The explanation of the link between glucose intolerance and increased liability to atherosclerosis is less certain. A variety of possible mechanisms have been proposed and are discussed elsewhere (for review, see Lundbaek \& Keen, I971) but, perhaps, the most persuasive ones at present are those that involve the intermediate agency of altered lipid metabolism. It is a well-established observation that hyperlipidaemia is a common accompaniment of diabetes in man (Klemperer, 1910; 
Albrink \& Man, 1958); in a little recognized observation in the eighteenth century, Matthew Dobson (1776) of Liverpool described the persistent milkiness of the serum in a diabetic patient at the same time as he made his original observations on the high-sugar content of blood and urine. From another standpoint, several of the genetic types of hyperliproproteinaemia described by Frederickson, Levy \& Lees ( 1967 ) are characterized by impairment of glucose tolerance in a high proportion of cases, amounting to treatable diabetes in some.

We examined the relationship between glucose tolerance and plasma lipid levels in a normal population sample consisting of ostensibly healthy employees of a large pharmaceutical company in London, selecting a sample of 220, stratified by age and sex, from approximately 1000 eligible subjects (Abrams, Jarrett, Keen, Boyns \& Crossley, 1969; Boyns, Crossley, Abrams, Jarrett \& Keen, I969). In addition to standard glucose tolerance tests and assay of accompanying insulin concentrations, glyceride and cholesterol concentrations were estimated in fasting blood samples. A striking degree of correlation $(r=0.734, P<0.001$ in men; $r=0.376, P<0.001$ in all women; $r=0.712 P>0.00 \mathrm{I}$ in women of 45 years and over) was found between fasting plasma glycerides and glucose tolerance as summarized by the area under the 2 -h blood-sugar curve. Across this normal range of glucose tolerance, the higher the fasting triglyceride concentration, the greater the area under the glucosetolerance curve (therefore, in relative terms, the greater the degree of glucose intolerance).

The relevance of hyperglyceridaemia to the development of atherosclerosis, first suggested by Albrink \& Man (1959) and subsequently supported by Brown and his collaborators (Brown, Kinch \& Doyle, I 965) have recently received further powerful support from the long-term study in Stockholm published by Carlson \& Böttiger (1972). They showed excess morbidity and mortality in subjects with raised triglyceride concentrations in a prospective ro-year study. In its predictive power, a raised triglyceride concentration at least equalled that of a raised blood cholesterol concentration, though the cut-off levels selected make the complete independence of the two measurements uncertain.

The role of insulin. There remain many unanswered questions. What is the nature of the relationship between the degree of glucose tolerance or intolerance and circulating triglyceride levels? Does a high circulating triglyceride concentration lead directly to impairment of glucose tolerance, perhaps by way of antagonism of insulin action? Recent experiments make this seem unlikely (Gibson, Grainger, Keen \& Jarrett, 1972). The blood-sugar response to an oral load of $50 \mathrm{~g}$ glucose was closely followed in fifteen metabolically normal subjects, by itself and in association with an intravenous injection of the triglyceride emulsion, Intralipid ( $1 \mathrm{ml} /$ $\mathrm{kg}$ body-weight), given at the same time as the glucose drink, and causing an acute rise in serum triglyceride concentrations to very high levels. There were only trivial differences in the curve of blood sugar and the accompanying insulin responses were virtually identical. Furthermore, glucose intolerance is not a feature of chronic fat-induced hyperlipaemia (Frederickson et al. 1967). Bierman (1972) has also shown that the glucose intolerance of spontaneously occurring endogenous 
hypertriglyceridaemia is not improved when serum triglyceride concentrations are brought down to normal by clofibrate administration. However, both hypertriglyceridaemia and hyperglycaemia respond promptly to dietary carbohydrate restriction and the role of dietary carbohydrate in promoting both abnormalities is well recognized. I will venture no further into a dangerous field than to say that the type, as well as the quantity, of dietary carbohydrate may be of importance in connexion with the metabolic phenomena.

Up to a certain point, increasing degrees of glucose intolerance are accompanied by progressive raising of circulating insulin concentrations. For some, this is evidence of the loss of peripheral insulin 'effectiveness' in the pathogenesis of diabetes (Reaven, Olefsky \& Farquhar, 1972); for others (Perley \& Kipnis, 1966) it betrays inadequacy of the pancreatic $\beta$-cell response. Whatever produces it, however, the hyperinsulinaemia of glucose intolerance may be the atherogenic culprit. Insulin may promote the hepatic synthesis of triglyceride-rich circulating lipoproteins (Farquhar, Reaven, Wagner \& Gross, 1966); insulin may stimulate lipogenesis and hinder lipolysis (Mahler, 197I) in the arterial wall itself. All these mechanisms favour the accumulation of intimal lipid. Hyperinsulinaemia may occur in the absence of significant hyperglycaemia in close relatives of diabetics (Reaven $e t$ al. 1972), in the obese (Karam, Grodsky \& Forsham, I968) and in subjects on high dietary intakes of carbohydrate--perhaps sucrose (Farquhar et al. 1966). Insulin action may thus represent one of the important final pathways of atherogenesis mentioned in the introduction.

\section{Dissociation of diabetes and atherosclerosis}

I would like to conclude with an apparent epidemiological anomaly, one of several in the relationship between diabetes and arterial disease. A Japanese physician who had spent several years working in a notable USA diabetes centre recently remarked to me that, since his return to Japan, he had been struck by the rarity of diabetic gangrene and clinical coronary disease in Japanese diabetics (E. Miki, personal communication). This clinical impression is supported by scanty published material (Kuzuya \& Kosaka, I97I). A comparison of post-mortem findings (Goto \& Fukuhara, I968) shows a most striking deficit in the representation of coronary disease as a cause of death in Japanese diabetics (5\% of 865$)$ compared with American diabetics ( $54 \%$ of $\mathrm{I} 283$ ), a difference too large to be accounted for by variation in autopsy methods or criteria. There is also strong evidence indicating very low prevalence and incidence of coronary disease in non-diabetic populations in Japan compared with the USA from the study 'Coronary Heart Disease in Seven Countries' of Keys and his colleagues (Keys, I970). From this, one may conclude the diabetic is not inevitably condemned to atherosclerotic disease as an integral part of the diabetic syndrome. Rather, the diabetic may be a particularly sensitive indicator of some atherogenic factor in the environment which, in Western countries, reflects itself in the generally high prevalence in the population. Argument by analogy is a treacherous friend but one might see a parallel in the disappearance of tuberculosis as a serious hazard for the diabetic as the prevalence of the condition has declined in 
the population as a whole. The considerable disparity of atherosclerosis frequency between geographically distinct groups of diabetics may help in the identification of some important environmental atherogenic factor which can in its turn be eradicated.

\section{REFERENCES}

Abrams, M. E., Jarrett, R. J., Keen, H., Boyns, D. R. \& Crossley, J. N. (1969). Br. med. \%. i, 599.

Albrink, M. J. \& Man, E. B. (1958). Diabetes 7, 194.

Albrink, M. J. \& Man, E. B. (I959). Archs intern. Med. ro3, 4.

Bennett, P. H., Burch, T. A. \& Miller, M. (197 I). Lancet ii, 125.

Bierman, E. (1972). Nutritional Factors in Diabetes. vi Capri Conference. (In the Press.)

Boyns, D. R., Crossley, J. N., Abrams, M. E., Jarrett, R. J. \& Keen, H. (I969). Br. med. Ұ. i, 595.

Brown, D. F., Kinch, S. H. \& Doyle, J. T. (I965). New Engl. J. Med. 273, 947.

Carlson, L. A. \& Böttiger, L. E. (1972). Lancet i, 865.

Dobson, M. (1776). In Medical Observations and Enquiries by a Society of Physicians in London Vol. 5, p. 298. London: T. Cadell in the Strand.

Epstein, F. H. (1967). Circulation 36, 609.

Eschwège, E. (1967). Bull. Inst. Natn. Santé Rech. Méd. 22, 264.

Farquhar, J. W., Reaven, G. M., Wagner, R. M. \& Gross, R. C. (I966). F. clin. Invest. 43, 1299.

Frederickson, D. S., Levy, R. I. \& Lees, R. S. (1967). New Engl. F. Med. 276, 34, 94, 148, 2 I 5 and 273.

Gelin, J., Elgrishi, I., Ducimetière, P. \& Richard, J. L. (1967). Bull. Inst. Natn. Santé. Rech. Méd. 22, 182 .

Gibson, T. R., Grainger, S., Keen, H. \& Jartett, R. J. (1972). Nutritional Factors in Diabetes vi Capri Conference (In the Press.)

Gofman, J. W., Hanig, M., Jones, H. B., Lauffer, M. A., Lawry, E. Y., Lewis, L. A., Mann, G. V., Moore, F. E., Olmsted, F., Yeager, J. F., Andrus, E. C., Barach, J. H., Beams, J. W., Fertig, J. W., Page, I. H., Shannon, J. A., Stare, F. J. \& White, P. D. (1956). Circulation r4, 691.

Gordon, T. (1964). Vital and Health Statistics, Series I I, no. 2. Washington, DC: US Government Printing Office.

Goto, Y. \& Fukuhara, N. (1968). Diabetes (Fapan) 11, 197.

Kannel, W. B., Castelli, W. P. \& McNamara, P. M. (1967). F. occup. Med. 9, 6r I.

Karam, J. H., Grodsky, G. M. \& Forsham, P. H. (I968). Am.F. clin. Nutr. 21, I 445.

Keen, H. (1971). Acta diabet. lat. Suppl. no. 1, p. 444.

Keys, A. (editor) (1970). Circulation 4I, Suppl. no. I.

Kingsbury, K. J. (1966). Lancet ii, 1374.

Klemperer, G. (1910). Dt. med. Wschr. 36, 2373 .

Kuzuya, N. \& Kosaka, K. (197I). In Diabetes Mellitus in Asia, r970. p. I I [S. Tsuji and M. Wada, editors]. Amsterdam: Excerpta Medica.

Lundbaek, K. \& Keen, H. (editors) (1971). Acta diabet. lat. 8, Suppl.

Mahler, R. (1971). Acta diabet. lat. 8, Suppl. no. I, p. 68.

Mimura, G., Oshiro, S., Koganemaru, K., Haraguchi, Y., Jinnouchi, T. \& Haraguchi, J. (1964). Kumamoto med. $7 . \mathbf{1 7}, 45$ and 50.

Mitchell, J. R. A. \& Schwartz, C. J. (I965). Arterial Disease p. 97 Ist ed. Oxford: Blackwell Scientific Publications Ltd.

Ostrander, L. D. Jr, Francis, T., Hayner, N. S., Kjelsberg, M. O. \& Epstein, F. H. (1965). Ann. intern. Med. 62, 1188.

Pell, S. \& D'Alonzo, C. A. (1970). भ. Am. med. Ass. 214, I833.

Perley, M. \& Kipnis, D. M. (I966). Diabetes 15, 867 .

Pyke, D. A. (I968). In Clinical Diabetes and its Biochemical Basis p. $53^{\circ}$ [W. G. Oakley, D. A. Pyke and K. W. Taylor, editors]. Oxford and Edinburgh: Blackwell Scientific Publications Ltd.

Reaven, G. M., Olefsky, J. \& Farquhar, J. W. (1972). Lancet i, 1247.

Sharp, C. L., Butterfield, W. J. H. \& Keen, H. (1964). Proc. R. Soc. Med. 57, 193.

Tzagournis, M., Seidensticker, J. F. \& Hamwi, G. J. (1967). Ann. intern. Med. 67, 42.

Wahlberg, F. (1966). Acta med. scand. 180, Suppl. p. 453.

Welborn, T. A., Curnow, D. H., Wearne, J. T., Cullen, K. J., McCall, M. G. \& Stenhouse, N. S. (1968). Med. $\Im$. Aust. 2, 778 .

Welborn, T. A., Jenkins, D. J. A., Cumpston, G. N., Curnow, D. H., Goff, D. V., Johnstone, C. J., Stenhouse, N. S. \& Summers, M. (1970). In Atherosclerosis: Proceedings of the Second International Symposium p. $3^{69}$ [R. J. Jones, editor]. Berlin, Heidelberg and New York: Springer-Verlag.

Printed in Great Britain 